\title{
Espírito e Vontade: uma relação entre os conceitos de Hegel e Schopenhauer
}

\author{
Autora: Laura Borba Moosburger*
}

August 11, 2008

\begin{abstract}
Resumo: Nosso intento é compreender o conceito de Espírito (Geist) em Hegel e o conceito de Vontade (Wille) em Schopenhauer como duas formas opostas e complementares de interpretação do "em-si", herdado da Crítica de Kant. Gostaríamos de observar de que maneira esses dois pensadores extraíram conseqüências tão distintas e, contudo, ambas a partir de uma mesma expressão fundamental da Crítica. Assim, o próprio "emsi" no sentido de Kant comportaria essas possibilidades interpretativas.

Palavras-chave: filosofia transcendental, razão, em-si, fenômeno, Espírito, Vontade.

Abstract: I intend to explain the concept of Spirit (Geist) on Hegel and the concept of Will (Wille) on Schopenhauer as two opposite and complementary ways of interpretation of the "in-itself", inherited from Kant's Critique. I'd like to observe how these both thinkers have extracted so different consequences and, nevertheless, from one and same fundamental expression of the Critique. Thus, the very "'in-itself" in Kant's sense would comport these interpretive possibilities.

Keywords: transcendental philosophy, reason, Spirit, Will.
\end{abstract}

Hegel e Schopenhauer respondem, segundo lógicas de pensamento diferentes, ao enlace entre a subjetividade transcendental "que diz respeito ao nosso eu como uma capacidade (Vermögen)" e o aparecimento do real, os fenômenos. De acordo com a "revolução copernicana" na filosofia de Kant, esse enlace responde ao fato de que não criamos o mundo dos fenômenos ao conhecê-lo, mas, ao mesmo tempo, o que este mundo é enquanto fenômeno origina-se do modo de ser de nossa capacidade fundamental de conhecê-lo: a razão.

Tudo aquilo que é, o mundo com todos os seres e eventos, vêm a ser a partir da imanência das possibilidades da razão pura. "Imanência" significa que esta razão pura não é para ser compreendida como razão divina, transcendente ao mundo. Com essa tese, Kant teria posto por terra as metafísicas anteriores, cuja pretensão era conhecer as coisas a partir do intelecto divino e tais como criadas por este mesmo intelecto. Se não criamos os fenômenos, deve haver algo que

*E-mail: lauramoosburger@uol.com.br 
seja em si, algo que corresponda ao fenômeno, mas não seja nunca fenômeno. Eis um sentido fundamental para a "coisa em si". Ora, a própria razão, porém, foi ao mesmo tempo descrita, na Crítica, como uma atividade em si mesma que constitui a totalidade do fenômeno enquanto aquilo que aparece segundo a sua capacidade (da razão) de conhecê-lo. Inclusive a suposição de um em-si do fenômeno provém da atividade em si da razão; ela constitui, precisamente, a totalidade da própria possibilidade do fenômeno.

Todavia, diante dessa estratégia, fica aberta a seguinte questão: como as coisas são como são? Ocorre no mundo uma diversidade de fenômenos, os quais possuem regras de permanência e causas de aparição e desaparição. Além disso, os fenômenos possuem feição própria e determinada. Por exemplo, a síntese que estrutura os fenômenos tem de ser, assim, fundamentalmente, uma atividade figurativa, geradora, por construção (mediante esquemas), dos entes - uma atividade que os delimite em seus aspectos próprios. Esta atividade, por sua vez, é precisamente o que parece furatar-se à análise da Crítica, e é, em certo sentido, o limite para o qual Kant aponta: a Crítica explica o que já não mais pode provar.

Tome-se por exemplo disso o desenvolvimento de uma passagem na qual Kant examina um objeto empírico da mais insuspeita trivialidade:

"O conceito de cão significa uma regra segundo a qual a minha imaginação pode traçar de maneira geral a figura de certo animal quadrúpede, sem ficar restringida a uma única figura particular, que a experiência me oferece ou também a qualquer imagem possível que posso representar in concreto" (CRP A 141, p.183).

Com efeito, Kant fala aqui do conceito de cão; porém, é o próprio cão empírico, o existente, que é possível apenas mediante a figuração esquemática da razão. Então o cão nada mais é que um produto da atividade figurativa da razão. No limite, não só o cão, como todos os entes, inclusive o ser humano empírico, são construídos esquematicamente pelo intelecto. Essa construção, por sua vez, é o ato mesmo de origem, daí que tenha de permanecer inacessível até mesmo à Crítica:

"Este esquematismo do nosso entendimento, em relação aos fenômenos e à sua mera forma, é uma arte oculta nas profundezas da alma humana, cujo segredo de funcionamento dificilmente poderemos alguma vez arrancar à natureza e pôr a descoberto perante os nossos olhos" (CRP B 118, p.184).

Com isso, a idéia de um "em-si", após Kant, tem de significar a totalidade do ser imanente aos fenômenos; porém, resta a seguinte ambigüidade: ou o em-si de todos os fenômenos é derivado da atividade em si da razão, ou, ao contrário, o em-si quer dizer algo de totalmente oposto ao modo de ser da razão.

As interpretações de Hegel e Schopenhauer, respectivamente pelos conceitos de Espírito e Vontade, seguirão cada uma um desses dois caminhos, como buscaremos mostrar. Esses conceitos, Espírito e Vontade, deixam-se compreender 
já pelo modo como Hegel e Schopenhauer entendem o que seja o conceito enquanto tal, o elemento em que por excelência se move o filósofo. Trata-se aqui, é claro, do modo como eles concebem o ponto de partida, o alcance e sentido do filosofar.

Hegel está, literalmente, em seu elemento - o conceito (Begriff) é o elemento da filosofia. Para o filósofo, o conceito abstrato é o que há de mais concreto, pois ele o compreende internamente mas ao mesmo tempo pela capacidade de abstração que permite ver o conceito em sua totalidade (portanto "de fora"). Begriff, o que "pega", "agarra" (greifen significa agarrar, apanhar) é o modo de ser do próprio Espírito, que ao se desenvolver em fenômenos agarra a si mesmo e se consolida em sua essência. Assim, o conceito é o máximo abarcante, o universal que toma para si o que é seu de direito. A dialética dos fenômenos do Espírito é a conquista progressiva do conceito, sua auto-exposição "exposição de seu agarrar-se antecipado a si" ao mesmo tempo em que é a elevação do filósofo (que escreve Fenomenologia do Espírito) conforme à sua essência espiritual, seu agarrar-se a si mesmo. A dialética finaliza-se na reunião da diversidade, na harmonia de todas as tensões.

Schopenhauer, por seu turno, inicia O Mundo como Vontade e Representação elevando o conceito ao que, em sus termos, significa a derradeira lucidez a que o homem pode chegar: a lucidez filosófica - a filosófica "posse dos próprios sentidos", correspondente ao "estar iluminado pelo sol" (Besonnenheit). Porém, no decorrer do livro, torna-se mais e mais claro que essa luz é derivada de uma experiência mais originária, e o conceito revela-se, apenas, espelho daquilo que em sua essência não é nada como conceito, mas seu oposto: o obscuro e incompreensível (Abgrund) - e nesse sentido derradeiro o conceito já é inteiramente passivo e estéril. O que acontece ao filósofo, então, é aperceber-se de que não está na posse de si mesmo - exato contrário do conceito hegeliano que ao desenvolver-se consolida a si mesmo - mas na posse de um saber que, em última instância, não dá conta de si mesmo.

Igualmente o estatuto da ciência, o modo de conhecimento rigorosamente conceitual, irá opor-se entre Hegel e Schopenhauer. Isto é, a meta da filosofia, como a entende Hegel, é científica:

"O espírito, que se sabe desenvolvido assim como espírito, é a ciência. A ciência é a efetividade do espírito, o reino que para si mesmo constrói em seu próprio elemento" (PHG, 1992, p.34).

A respeito desse mote Hyppolite esclarece que a filosofia, em sentido hegeliano (Hyppolite se refere às obras filosóficas de Iena) não é uma lógica como organon - lógica que trata apenas do instrumento do saber, antes do saber, nem um amor da verdade que não seja já a possessão mesma da verdade.

Nesse sentido, para Hegel, a Filosofia é, desde seu ponto de partida, ciência do Absoluto. Como tal, não lhe cabe permanecer "numa reflexão esvaziada, no saber do saber" mas é preciso "mergulhar direta e imediatamente no objeto a conhecer, denomine-se este Natureza, Universo ou Razão absoluta" ${ }^{1}$. Per-

${ }^{1}$ (HYPPOLITE, 1999, p. 21) 
manecer na reflexão seria não compreender que a esta última já pressupõe o refletido, isto é, o objeto, no ato mesmo de refletir. Por esta razão, o pensamento de Hegel requer uma superação da posição de crítica do conhecimento por parte do sujeito como fizera Kant.

Contudo, Hyppolite também observa que a Fenomenologia do Espírito, especialmente, revê esta necessidade de superação: Hegel retoma suas críticas a uma filosofia que se resignasse a ser somente uma teoria do conhecimento, mas também retorna de certo modo ao ponto de vista kantiano. Não por deter-se na crítica da faculdade de conhecimento em suas possibilidades constituídas, e sim por via justamente da noção de alienação e de ascese do saber comum ao saber absoluto ${ }^{2}$.

É preciso, portanto, que o pensador hegeliano se desloque para o ponto de vista do absoluto para que possa, simplesmente, iniciar esta ascese; ou seja, é preciso que o filósofo "se mova no cerne do conceito" . Nesta acepção a filosofia, como auto-saber do Espírito, é a ciência das ciências. Nos termos de Hegel, o Espírito se faz objeto de si mesmo, e sua forma é o que ele mesmo é, já que ele é seu tornar-se, e assim o próprio modo de ser do conceito é ser contra si:

"O puro reconhecer-se-a-si-mesmo no absoluto ser-outro, esse éter como tal, é o fundamento e o solo da ciência, ou do saber em sua universalidade. O começo da filosofia faz sua pressuposição ou exigência de que a consciência se encontre nesse elemento. Mas esse elemento só alcança sua perfeição e transparência pelo movimento de seu vir-a-ser. É a pura espiritualidade como o universal, que tem o modo da imediatez simples (...)" (HEGEL, 1992, p.34).

Na contrapartida Schopenhaueriana, o conceito não assume a imediatez mais simples, pelo contrário, é uma representação abstrata - que faz abstração justamente daquilo que é mais próprio e verdadeiro na representação intuitiva (isto é, na representação que se doa imediatamente para o conhecimento).

Enquanto a ciência ordena o conhecimento intuitivo em esquemas conceituais, a filosofia toma para consideração em primeiro lugar o fato do acontecimento do mundo como intuição imediata e daí passa a decifrar o significado desta doação, observando a imagem daquilo que se apresenta. Para o filósofo schopenhaueriano, seguir o procedimento científico seria "tentar entrar em uma fortaleza dando voltas ao seu redor, buscando em vão por uma porta e de vez em quando desenhando as fachadas". A ciência para onde começa a filosofia: considera as leis de aparição dos fenômenos, mas se interrompe na interpretação do ser mesmo que se faz fenômeno. O que para a ciência é uma intransponível qualitas occulta é para a filosofia a questão mesma a ser desvendada.

Aqui não é o modo de ser do conceito que é ser-contra-si, mas, diferentementemente, o modo de ser do conceito está contra si mesmo na destinação da filosofia. Esta primeira indicação conduz à própria separação entre os conceitos de Espírito (hegeliano) e Vontade (Schopenhaueriana). O conceito de Espírito sobressai em sua diversidade com relação ao natural em estado puro.

${ }^{2}$ Cf, Hippolyte, (idem, ib., pp. 22 e 23 ) 
Observe-se, para ressaltar isso, como Hegel se utiliza de exemplos da natureza para ilustrar a dialética do vir-a-ser: o botão, diz ele, desaparece no desabrochar da flor, e poderia dizer-se que a flor o refuta. Novamente, o fruto faz a flor aparecer como um falso ser-aí da planta, pois ele é agora sua verdade. Essas formas não são apenas distintas, mas se repelem mutuamente. Todavia, a natureza fluída da planta reúne todos os seus momentos na unidade orgânica, na qual todos eles são necessários. Sim. Mas Hegel continua:

“... a contradição a um sistema filosófico não costuma conceberse desse modo; além disso, a consciência que apreende essa contradição não sabe geralmente libertá-la - ou mantê-la livre - de sua unilateralidade; nem sabe reconhecer no que aparece sob a forma de luta e contradição contra si mesmo momentos mutuamente necessários" (HEGEL, 1992, p. 22).

Apesar deste difícil reconhecimento, é o espiritual que por excelência está no modo de ser do devir dialético. E o fato de que geralmente ele não seja assim reconhecido, na verdade, deve-se justamente a isto. Pois o Espírito é dialético por isso, por estar de fato envolvido em um momento seu como em sua totalidade, e por ter de tornar-se outro, por força de seu próprio modo de ser, para então se retomar numa totalidade que reconciliou seus momentos contrários. A alteridade do Espírito consiste em ser capaz de ser mediação de si mesmo, o seu ser em-si e para-si - é sua 'alternalidade'.

Por força disso Hegel podia dizer que o Espírito é substância como sujeito, movimento de pôr-se a si mesmo ou a mediação de seu devir outro consigo mesmo. O Espírito é, enquanto sujeito:

"... negatividade pura e simples, e justamente por isso é o fracionamento do simples ou a duplicação oponente, que é de novo a negação dessa diversidade indiferente e de seu oposto. Só essa igualdade reinstaurando-se, ou só a reflexão em si mesmo no seu ser-Outro, é que são o verdadeiro; e não uma unidade originária enquanto tal, ou uma unidade imediata enquanto tal. O verdadeiro é o vir-a-ser de si mesmo, o círculo que pressupõe seu fim como sua meta, que o tem como princípio, e que só é efetivo mediante sua atualização e seu fim" (HEGEL, 1992, p. 30).

Ora, o conceito finito não se desenvolve além do que já contém em si, não se torna nunca, para si mesmo, o que é em si. Seu tornar-se é um fluir-em-outro, não um ter de se fazer outro. O Espírito somente, como consciência, é que se mediatiza em si mesmo, ele é na negatividade. Mas então transparece, para Hegel, que também o natural só pode perfazer-se por haver Espírito como a superfície de aparição - algo que se furtou ao esforço do interior da negatividade, sendo apenas fluir do que aparece, na seqüência de seus momentos.

Isso fica ainda mais claro pelo exemplo destacado da gênese do próprio ser humano, como fornecido por Hegel: 
"Se o embrião é de fato homem em si, contudo não o é para si. Somente como razão cultivada e desenvolvida ? que se fez a si mesma o que é em si ? é homem para si; só essa é sua efetividade. Porém esse resultado por sua vez é imediatez simples, pois é liberdade-consciente-de-si que em si repousa, e que não deixou de lado a oposição e ali a abandonou, mas se reconciliou com ela" (HEGEL, 1992, p.31)

Ou ainda:

"O verdadeiro é o todo, e o todo reside somente a essência que se implementa através de seu desenvolvimento".

Seguindo a lógica do pensamento hegeliano, é o Espírito que, princípio e fim, já se implementou como outro também no embrião. Se fosse diferente, o em-si e o para-si não estariam na relação intrínseca de igualdade e diferença, mesmidade e alteridade. Ora, parece então que o Espírito absoluto potencializa a força da razão, mas agora em sentido kantiano, de tal modo a fazer de todo o real uma emanação de nossa essência, o Espírito.

Nesse sentido, tudo o que em nós não é espiritual é o Espírito que se encontra ainda alienado, porque ainda não se desvencilhou do outro que se levanta para si (para o Espírito) como o a-ser-superado. Este outro tem de provir do próprio Espírito, pois sua alienação é sempre com relação a si mesmo, e não a qualquer outro absolutamente (como uma natureza ou Deus inacessíveis) senão o Absoluto não seria Absoluto. A natureza não se faz a si mesma outro do Espírito - o Espírito é que, mediação de si mesmo, põe-se como outro enquanto natureza.

Com efeito, como aludimos inicialmente, este resultado parece ser uma possibilidade inscrita na própria Crítica kantiana. Pelo menos na medida em que, ao privar do conhecimento um fundamento nas coisas em si mesmas no sentido de coisas concebidas oucriadas por um Deus, acima de nossa razão finita, deslocou-se este fundamento para o interior da subjetividade. E isto de tal de modo que, até certo ponto, a infinitude criadora do objeto fenomênico - outrora propriedade de Deus - passa a ser algo em nós mesmos do qual não nos tornamos plenamente conscientes, pois não podemos deixar de lado nossa finitude e observar a totalidade do engendramento do objeto fenomênico.

Essa, pelo menos, parece ser uma conseqüência do que afirma Hyppolite quando advertia que a Crítica, ao condenar toda metafísica do objeto ou do ser (como havia sido toda metafísica até então), continha em germe uma metafísica de outra ordem, uma metafísica do sujeito ${ }^{3}$. Com Hegel, então, o fato do filósofo tornar-se plenamente consciente do engendramento do objeto fenomênico faz possível a realização máxima do Espírito enquanto saber de si, como ciência, filosofia. A partir da filosofia, e em conseqüência de seu particular estatuto, os objetos de outras ciências podem ser compreendidos em suaser totalidade, já que o Espírito, no movimento de auto-conhecimento, é a própria forma da totalidade.

${ }^{3}$ (HYPPOLITE, 1999, p. 158) 
Em contraponto preciso, Schopenhauer dá outro encaminhamento à Crítica: vê na subjetividade transcendental a condição de possibilidade da forma dos fenômenos, mas não a condição daquilo que os fenômenos são verdadeiramente, em si mesmos. Para ele, a expressão "em-si" já diz que designa o oposto de tudo o que conhecemos conscientemente e se mostra para nós. A saber, de tudo o que aparece e somos capazes de conceber - e, por que não, de tudo que consideramos espiritual, sobretudo no sentido de Hegel, para quem o espiritual irmana-se ao que é objetivo, abarcável pelo conceito.

Assim, aquelas características do Espírito que acontecem apenas para o cumprimento de sua superação derradeira, a saber, a inconsciência, o não-saber de si, para Schopenhauer são o fundo sem fundo (Abgrund) de tudo o que aparece. Inclusive de nós mesmos e, ainda, de tudo o que em nós é considerado espiritual. Este "em-si" é então a Vontade, o próprio Nada que, querendo a si mesmo, irrompe na profusão fenomênica:

"No fundo, o que encontramos é isto: que a Vontade se devora a si mesma, porque fora dela nada existe e é uma Vontade faminta. Daí a caça, a angústia e a dor". (SCHOPENHAUER, 1999, p. 217).

Este "cravar os dentes na própria carne" corresponde, para Schopenhauer, ao próprio ato de criar carne e dentes, a partir do nada. Por certo, para o autor do Mundo como Vontade e como Representação, o "em-si" irrompe em um "forade-si", mas agora, unicamente porque é cego. Não mais a "inquietude do Si semovente", do Espírito hegeliano, mas o ímpeto cego, a fome insaciável da Vontade.

Nesta manifestação da Vontade, ainda há uma dialética das formas que a Vontade vai assumindo, formas que progridem apenas em complexidade, ao assimilarem formas mais simples. Schopenhauer distinguiu estas formas, como Idéias, do conceito, pois não são unidades abstraídas de conjuntos (como é o conceito segundo ele), e não progridem em direção a um fim último, como o Espírito. A Idéia é um ato-em-si da Vontade, ato indiviso no qual se dá a reunião e divisão do ser: a própria unidade-dúplice originária que é a Vontade.

Aí, segundo a descrição schopenhaueriana, "não há tempo" para uma dialética em sentido hegeliano, de um aperfeiçoamento de si. O conceito (em sentido hegeliano), no seu elemento, seguia o caminho da dialética e assim se desenvolvia, expondo-se para si mesmo. O tempo, ele mesmo, consistia em um elemento do Espírito. Era o que sugeria o exemplo hegeliano segundo o qual, como vimos acima, o fluir da planta era derivado. Para Schopenhauer há que se notar duas diferenças fundamentais. Primeiro, o ato de engendramento da forma da planta seria "em si" sem pressupor um ser-para-si (prerrogativa do conceito). Depois, sua exposição no tempo seria apenas manifestação temporal de algo que já é o que é, "em si". Não é isto exatamente aquilo que Hegel parece negar em relação ao Espírito: sua apreensão em uma unidade originária?

Mas é preciso também resaltar que Schopenhauer entende o tempo de forma distinta de Hegel. Ele interpreta, a partir de Kant, que a idealidade do tempo restringe este ao nosso modo de conhecimento e logo aos fenômenos cognoscíveis. 
Todavia, aquilo mesmo que entra na temporalidade, a Vontade em si, não é submetida ao tempo. Schopenhauer permanece profundamente kantiano ao chegar a essa conclusão, se temos em mente que a temporalidade significa já consciência do tempo: isto é, se aquilo que é em si não é temporal, e, por força disso, também inconsciente. A estética Transcendental pressupunha que toda sucessão pressupusesse consciência.

Mas como a essência daquilo que sucede é intemporal, conseqüentemente, não pode haver nenhum progresso, e a sucessão no tempo-consciência não pode passar de exposição do não-consciente. è o que parece tern notado Philonenko, quando entende que a teoria da idealidade do tempo conduziu Schopenhauer a recusar em definitivo a filosofia da história no sentido de Hegel. Não pode haver salvação proveniente da história. A mirada filosófica descobre, com melancolia, que a nesciedade e a crueldade se repetem incansavelmente:

"... a guerra nunca ensinou nada a ninguém, e o sangue corre sempre tão vermelho hoje como desde há séculos". (PHILONENKO, 1989, pp. 96 e 97$)$

A intuição filosófica fundamental de Schopenhauer é o próprio absurdo, uma visão do mundo em oposição completa a toda espécie de justificação, um "sentimento de estranheza absurdo diante da simples noção de existência" ${ }^{4}$.

Retomemos então a comparação que propunhamos no início de nossas considerações. O conceito de Espírito e o de Vontade não são apenas opostos: cada qual encerra uma lógica oposta e simétrica à do outro e, com ela, uma argumentação que se sustenta em si. De tal modo que, sua dialética (a desses conceitos) chega a desenhar, de certa forma, a dialética das dialéticas - põe em quessertão a própria possibilidade da dialética hegeliana como tal.

Essa última repousava em que a autoconsciência a ser atingida - a totalidade do fenômeno (em termos kantianos) - já se encontra no início, na antecipação de seu fim. Em outras palavras, o "em-si" vem a ser "para-si". O conceito de Vontade, em contrapartida, não apenas transfere a inconsciência para o princípio, pensando o em-si como o abafamento obscuro que difere inteiramente do mundo representado ${ }^{5}$, mas também compreende de fato uma dialética. Só que, agora, esta é inconsciente, a saber, a luta sem fim da Vontade cega, a qual, ainda que tenha originado a visão e o espírito, por ser cega engendra formas e nunca pode satisfazer-sepor não deixar de ser, em si mesma, falta.

A metafísica do sujeito que, segundo Hyppolite, os intérpretes de Kant aduziram da Crítica, apresenta-se também em Schopenhauer, tomando a singular feição de um sujeito destituído de si, estranho a si, de um querer que o sujeito já não pode querer, um saber que escapa ao saber.

Mais um motivo para que, sob a filiação comum aos temas kantianos, se leve a cabo uma comparação entre dois resultados tão disitintos, e ao mesmo tempo aparentados, como os que decorrem da filosofia de Hegel e da de Schopenhauer.

\footnotetext{
${ }^{4}$ (ROSSET, 1967, p. 64)

${ }^{5}$ Mas que com este desfecha a totalidade do fenômeno (como emKant).
} 
É perfeitamente comprensível, no entanto, que dois irmãos kantianos possam ter fisionomias tão dissemelhantes, quando examinados no detalhe.

\section{References}

[1] HYPPOLITE, J.; Gênese e Estrutura da Fenomenologia do Espírito de Hegel. 1999. Trad. A. J. Vaczi, D. S. Cordeiro, G. Tedéia, L. S. Repa, R. A. do Nascimento. São Paulo: Discurso.

[2] HEGEL, G.W.F.; Fenomenologia do Espírito. 1992. $2^{\mathrm{a}}$ ed. Trad. Paulo Meneses com a colaboração de Karl-Heinz Efken. Petrópolis: Vozes.

[3] KANT, Immanuel.; Crítica da Razão Pura. 1997. $4^{\mathrm{a}}$ ed. Trad. Manuela dos Santos e Alexandre Morujão. Lisboa: Calouste Gulbenkian.

[4] PHILONEnKO, A.; Schopenhauer: Una Filosofía de la Tragédia. 1989. Trad. G. Muñoz-Alonso. Barcelona: Antrophos.

[5] ROSSET, C.; Schopenhauer, philosophe de l'absurde. 1967. Paris: Quadrige / Presses Universitaires de France.

[6] SCHOPEnHAUER, A.; Die Welt als Wille und Vorstellung, Felix Meiner Verlag, hambug, 1998. 